\title{
Erratum
}

\section{Bacteroides microfusus, a New Species from the Intestines of Calves, Chickens, and Japanese Quails CHOJI KANEUCHI AND TOMOTARI MITSUOKA}

The Institute of Physical and Chemical Research, Wako, Saitama, 351, Japan

Volume 28 , no. 4 , p. 479 , column 1: Figure 1 was inadvertently omitted. It should have been printed as shown below.

Fig. 1. B. microfusus ATCC 29728, the type strain. Cells from 24-h-old PYG broth culture. Bar represents $10 \mu \mathrm{m}$. 